\title{
Influence of Chamber Geometrical Parameters on Suppressing Explosion Propagation
}

\author{
Zhuo Yan $\mathbb{D}^{1,2,3}$ Shengli Guo, ${ }^{3}$ Shujie Yuan $\mathbb{D}^{3},{ }^{3}$ and Chaomin $M u \mathbb{D}^{3}$ \\ ${ }^{1}$ State Key Laboratory of Mining Response and Disaster Prevention and Control in Deep Coal Mines, \\ Anhui University of Science and Technology, Huainan 232001, China \\ ${ }^{2}$ Institute of Energy, Hefei Comprehensive National Science Center, Anhui, Hefei 230031, China \\ ${ }^{3}$ School of Safety Science and Engineering, Anhui University of Science and Technology, Huainan 232001, China \\ Correspondence should be addressed to Shujie Yuan; yuansj@aust.edu.cn and Chaomin Mu; chmmu@mail.ustc.edu.cn
}

Received 7 July 2021; Accepted 16 August 2021; Published 31 August 2021

Academic Editor: Zhigang Tao

Copyright (C) 2021 Zhuo Yan et al. This is an open access article distributed under the Creative Commons Attribution License, which permits unrestricted use, distribution, and reproduction in any medium, provided the original work is properly cited.

\begin{abstract}
In this article, the effect of a chamber's geometrical parameters on suppressing gas explosion propagation was studied. Three rectangular chambers were used in the study, with a constant length of $0.5 \mathrm{~m}$, a constant height of $0.2 \mathrm{~m}$, and a variable width of $0.3 \mathrm{~m}, 0.5 \mathrm{~m}$, and $0.8 \mathrm{~m}$; each chamber was installed in a pipeline system for experimental research. The experimental results showed that when the chamber length and height were fixed at $0.5 \mathrm{~m}$ and $0.2 \mathrm{~m}$, respectively, the suppression effect of the chamber on the explosion shockwave improves with the increase in the chamber width; when the chamber width increases to $0.8 \mathrm{~m}$, the chamber has suppressive effect on explosion shockwave propagation. It was also found that the suppression effect of the chambers on the explosion flame improves with the increase in the chamber width; when the width of the chamber is $0.5 \mathrm{~m}$, the chamber effectively suppresses explosion flames. Based on the experimental results, a numerical model was established to simulate the suppression effect of five types of chambers with a length, width, and height of $0.5 \mathrm{~m} \times 0.3 \mathrm{~m} \times 0.2 \mathrm{~m}, 0.3 \mathrm{~m} \times 0.5 \mathrm{~m} \times 0.2 \mathrm{~m}$, $0.5 \mathrm{~m} \times 0.5 \mathrm{~m} \times 0.2 \mathrm{~m}, 0.5 \mathrm{~m} \times 0.8 \mathrm{~m} \times 0.2 \mathrm{~m}$, and $0.8 \mathrm{~m} \times 0.5 \mathrm{~m} \times 0.2 \mathrm{~m}$, respectively. The numerical simulation results indicated that when the chamber length and height are constant at $0.5 \mathrm{~m}$ and $0.2 \mathrm{~m}$, respectively, the suppressive effect of the chamber on the shockwave improves as the chamber width increases; when the chamber width increases to $0.8 \mathrm{~m}$, the shockwave overpressure at the chamber outlet is attenuated by $10.61 \%$, indicating that the chamber suppresses the propagation of explosion shockwave, which is consistent with the experimental results obtained in the study. It was also found that when the chamber width and height were constant at $0.5 \mathrm{~m}$ and $0.2 \mathrm{~m}$, respectively, as the chamber length increases, the overpressure increases first and then weakens. When the chamber length increases to $0.8 \mathrm{~m}$, the overpressure at the chamber outlet is attenuated by $-14.16 \%$, indicating that the chamber is not able to suppress the propagation of explosion shockwave. Finally, a numerical simulation of the propagation process of a methane-air mixture and explosion flames in different chambers was performed to analyse the effect of chamber geometrical parameters on explosion suppression effect.
\end{abstract}

\section{Introduction}

When gas explosions occur in coal mine tunnels and urban underground pipeline systems, a strong ultrahigh temperature flame and an enormous shockwave overpressure are generated instantaneously, which then rapidly propagate through the confined space of the tunnel or pipeline system, destroying surrounding facilities, causing a large number of casualties and property losses, and having a highly detrimental social and economic impact [1]. The development of explosion and flame suppression technology is important for the prevention and control of gas explosion accidents in mining tunnels and underground urban pipeline systems. To this end, much theoretical research and experimental investigations have been conducted in this field both at home and abroad; for example, Thomas, Pawel Kosinski, Mikhail Krasnyansky, Hermanns, Lu Shouxiang, Bi Mingshu, Yu Minggao, Xu Hongli, Wang Xishi, Wen Hu, Luo Zhenmin et al. [2-12] have conducted successful studies on gas explosion suppression using water mist, powder inhibitors, and 
inert gas technology. Shao Jiwei et al. [13] demonstrated experimentally that porous materials have an obvious explosion suppression effect. Zhao Kai et al. [14] found that the hollow cylindrical shell structure has a strong shock waveabsorbing and energy-absorbing effect, and it can withstand damage from repeated explosions. $\mathrm{Wu}$ and Jiang [15] designed a vacuum chamber based on the negative pressure principle of vacuum and installed it on an experimental pipeline; the study found that when the explosion propagated in the pipeline, the shockwave and flame produced by the explosion were sucked into the vacuum chamber owing to the negative pressure effect, thereby significantly suppressing the explosion overpressure and flames. Shao et al. [16-18] found that the effect of the vacuum chamber in suppressing gas explosion depends on the volume of vacuum chamber; when the chamber volume exceeds the critical volume, the vacuum chamber can effectively suppress gas explosions. On the contrary, when the chamber volume is smaller than the critical volume, not only does the vacuum chamber have no effect in suppressing gas explosion but also the shockwave overpressure and flame intensity are actually stronger than when no vacuum chamber is used. In addition, the vacuum degree has no obvious influence on the effect of the vacuum chamber in suppressing gas explosion. Li et al. [19] used rectangular chambers of different sizes installed on a $36 \mathrm{~m}$ long large-scale pipeline system for gas explosion experiment to conduct an experimental research, and they found that the chamber attached to the pipeline system has effect on shockwave suppression.

In practical applications, the chamber height is usually consistent with the height of a mine tunnel or an underground pipeline system, and the chamber size is changed by adjusting its length or width. However, there are few studies on how the change of chamber length or width affects its detonation suppression performance. The aim of this study is to explore the influence of the chamber width or length on its explosion suppression effect. To this end, we conducted a series of experiments and numerical simulations under the following two sets of conditions: (1) with the chamber height and length fixed and with variable width, and (2) with the chamber height and width fixed and with variable length, in order to better understand the effect of the geometric parameters of different rectangular chambers on the propagation of explosion shockwave and to analyse the effect of the geometric parameters of chambers on their effectiveness in gas explosion suppression.

\section{Experimental Study on the Explosion Suppression Effect of Chambers}

In this study, a series of experiments was carried out to investigate shockwave overpressure and flame data and to analyse the suppression effect of different chambers on shockwave propagation in gas explosions. To this end, three rectangular chambers with fixed height and length and a gradually changing width were installed in a gas pipeline system; the length, width, and height of the three chambers were $0.5 \mathrm{~m} \times 0.3 \mathrm{~m} \times 0.2 \mathrm{~m}, \quad 0.5 \mathrm{~m} \times 0.5 \mathrm{~m} \times 0.2 \mathrm{~m}$, and $0.5 \mathrm{~m} \times 0.8 \mathrm{~m} \times 0.2 \mathrm{~m}$, respectively, and the wall thickness of all three chambers was $0.01 \mathrm{~m}$.
2.1. Experimental System. The design of the experimental system is shown in Figure 1 . The $36 \mathrm{~m}$ pipeline system for gas explosion experiment consists of five parts: an explosion pipeline section, premixed gas preparation system, ignition system, data acquisition system, and chamber.

(1) The experimental pipeline is constructed of steel pipes with a diameter of $0.2 \mathrm{~m}$ and a thickness of $0.01 \mathrm{~m}$, with a pressure resistance of $20 \mathrm{MPa}$. The pipes are connected by flange plates with rubber and asbestos gaskets to ensure that the pipeline section is airtight. (2) The premixed gas preparation system consists of a gas tank, a vacuum pressure gauge, an air compressor, and a pump for circulating gas. The gas used in the present experiment is high-purity methane (over $99.9 \%$ purity). (3) The ignition system consists of a power supply, a fuse, conducting wires, and an ignition electrode. The electrode is placed on the flange at the end of the pipeline section, where it is ignited by the fuse; the ignition voltage is $36 \mathrm{~V}$, and the ignition energy is $10 \mathrm{~J}$. (4) The data acquisition system consists of pressure sensors, flame sensors, a flow transmitter, a data collector, and an operating unit. The pressure sensors $P_{1}$ and $P_{2}$, which have a detection range of 0 to $3 \mathrm{MPa}$ with an accuracy of $0.5 \%$ of FS, are placed at a distance of $13.25 \mathrm{~m}(0.25 \mathrm{~m}$ from the chamber's inlet) and $13.75+x \mathrm{~m}(0.25 \mathrm{~m}$ from the chamber's outlet, $x$ is the chamber's length), respectively, from the ignition electrode. The flame sensors $F_{1}$ and $F_{2}$ have a maximum sampling frequency of $20 \mathrm{Msps}$ with an accuracy of $0.1 \%$ of FS; they are placed at positions corresponding to the pressure sensors, respectively. (5) The length, width, and height of the three chambers are $0.5 \mathrm{~m} \times 0.3 \mathrm{~m} \times 00.2 \mathrm{~m}$, $0.5 \mathrm{~m} \times 0.5 \mathrm{~m} \times 00.2 \mathrm{~m}$, and $0.5 \mathrm{~m} \times 0.8 \mathrm{~m} \times 00.2 \mathrm{~m}$, respectively, as shown in Figure 2.

2.2. Experiment Design. Before starting the experiment, the pipes of the detonation system were connected, and a $0.4 \mathrm{~mm}$-thick polyethylene film was used to seal the detonation segment at a distance of $11 \mathrm{~m}$ from the ignition electrode. A positive displacement air compressor was then used to test the airtightness of each joint, and a vacuum pump was used to evacuate the air from the pipes. Next, a methane-air mixture was prepared based on Dalton's partial pressure principle, so that a $10 \%$ concentration methane-air mixture was used in each experiment, which is the optimal concentration to produce the highest explosion intensity under experimental conditions [20]. After preparing the gas mixture, a gas circulating pump was used to mix air and methane in the detonation segment into a homogenous mixture for 10 to $20 \mathrm{~min}$. After completing the mixing process, the ignition system was used to initiate the explosion. Once the explosion was initiated, the flame sensors and pressure sensors began to collect data, which were processed using the testing software DAP to generate flameand pressure-change curves. On completion of the experiment, an air compressor was used to force out any residual exhaust from the pipeline section.

The experiments are divided into four categories: (1) the propagation of gas explosion in a pipeline section without a chamber, where the chamber in Figure 1 is 


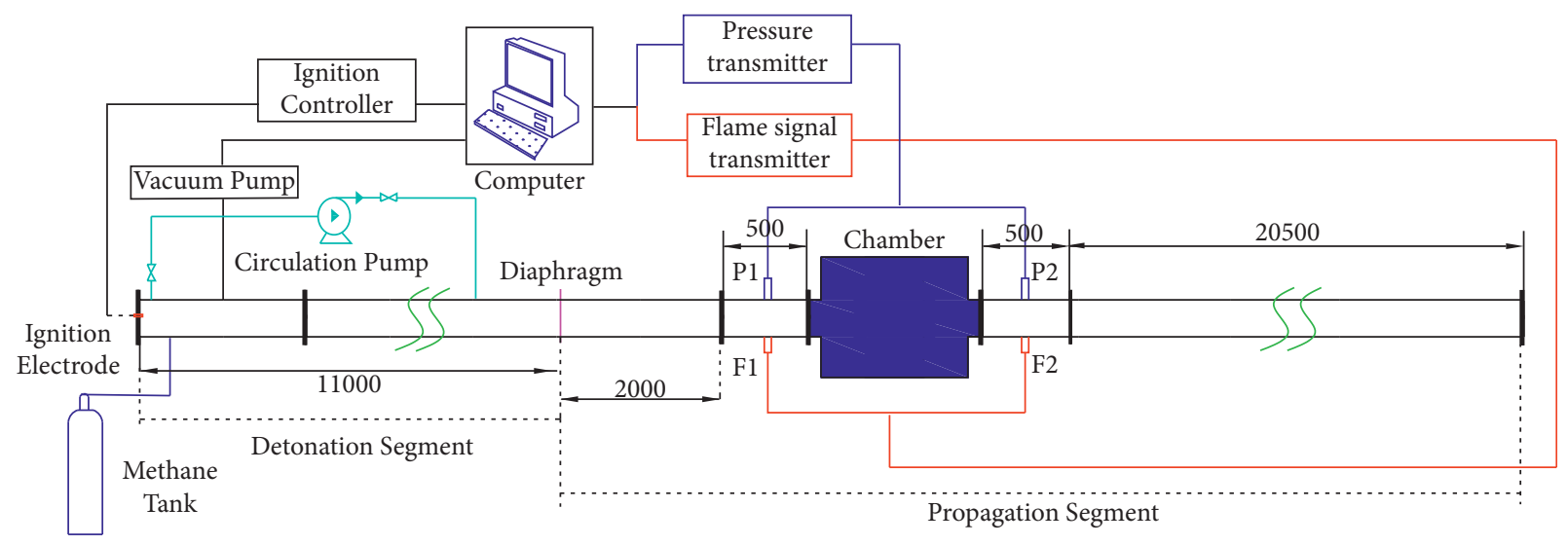

Figure 1: Chart of experimental system for gas explosion.

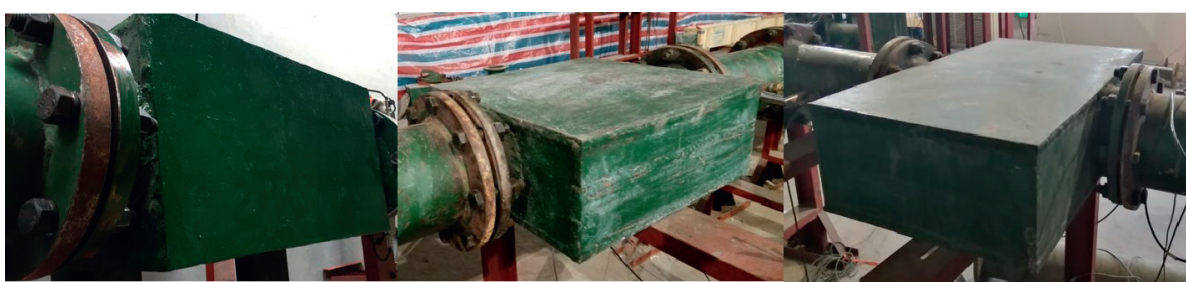

FigURE 2: Experimental rectangular chambers.

replaced by a $0.2 \mathrm{~m}$-diameter pipe with a length of $0.5 \mathrm{~m}$; (2) gas explosion suppression using a rectangular chamber of L0.5 m $\times \mathrm{W} 0.3 \mathrm{~m} \times \mathrm{H} 0.2 \mathrm{~m}$; (3) gas explosion suppression using a chamber of L0.5 m $\times$ W0.5 m $\times$ H0.2 m; and (4) gas explosion suppression using a chamber of L0.5 m $\times$ W0.8 m $\times$ H0. $2 \mathrm{~m}$.

\subsection{Experimental Results and Analysis}

2.3.1. Suppression of Explosion Shockwave by Chambers with Different Geometric Parameters. Figure 3 shows the overpressure-time curve of the gas explosion shockwave at each monitoring point of the propagation experiment of gas explosion in a pipeline section without a chamber and the explosion suppression experiments using different-size chambers.

Figure 3(a) shows that, in the pipeline section without a chamber, the maximum overpressure of the shockwave at the points $\mathrm{P} 1$ and $\mathrm{P} 2$ is $0.3208 \mathrm{MPa}$ and $0.3319 \mathrm{MPa}$, respectively; the attenuation ratio of the shockwave overpressure at P2 can be expressed as (0.3208-0.3319)/ $0.3208=-3.46 \%$, which means that from $\mathrm{P} 1$ to $\mathrm{P} 2$, the shockwave overpressure increases, so the explosion overpressure is in the rising phase.

It is evident from Figure 3(b) that when the chamber of L0.5 $m \times$ W0.3 $m \times H 0.2 \mathrm{~m}$ is used in the experiment, the maximum overpressure at the points $\mathrm{P} 1$ and $\mathrm{P} 2$ is $0.4367 \mathrm{MPa}$ and $0.4605 \mathrm{MPa}$, respectively, and after passing through the chamber, the explosion overpressure at P2 increases slightly and is attenuated by $-5.45 \%$. Compared with the pipeline section without a chamber, the relative overpressure attenuation ratio measured at $\mathrm{P} 1$ and $\mathrm{P} 2$ can be calculated as $(0.3208-0.4367) / 0.3208=-36.15 \%$ and $(0.3319-0.4605) / 0.3319=-38.7 \%$, respectively, which shows that the chamber actually increased the explosion overpressure.

Figure 3(c) shows that when the chamber of L0.5 $\mathrm{m} \times \mathrm{W} 0.5 \mathrm{~m} \times \mathrm{H} 0.2 \mathrm{~m}$ is used in the experiment, the maximum overpressure at $\mathrm{P} 1$ and $\mathrm{P} 2$ is $0.418 \mathrm{MPa}$ and $0.42 \mathrm{MPa}$, respectively, and after passing the chamber, the magnitude of the overpressure does not change significantly; the overpressure at P2 is attenuated by only $-0.47 \%$. Compared with the pipeline section without a chamber, the relative overpressure attenuation ratio at $\mathrm{P} 1$ and $\mathrm{P} 2$ is $-30.3 \%$ and $-26.5 \%$, respectively, which shows that this chamber causes an increase in the overpressure.

Figure 3(d) shows that when the chamber of $\mathrm{L} 0.5 \mathrm{~m} \times \mathrm{W} 0.8 \mathrm{~m} \times \mathrm{H} 0.2 \mathrm{~m}$ is used, the maximum overpressure at $\mathrm{P} 1$ and $\mathrm{P} 2$ is $0.3509 \mathrm{MPa}$ and $0.2927 \mathrm{MPa}$, respectively, and after the shockwave passes through the chamber, significant overpressure attenuation occurs at P2, with an attenuation ratio of $16.58 \%$. Compared with the pipeline section without a chamber, the overpressure attenuation ratio at $\mathrm{P} 1$ and $\mathrm{P} 2$ is $-9.38 \%$ and $11.8 \%$, respectively. Although the shockwave overpressure at the chamber inlet (P1) increased, the shockwave overpressure at the chamber outlet (P2) was significantly attenuated, which shows that this chamber has an attenuation effect on the explosion overpressure.

The results of these experiments show that when the chamber length and height are constant at $0.5 \mathrm{~m}$ and $0.2 \mathrm{~m}$, 


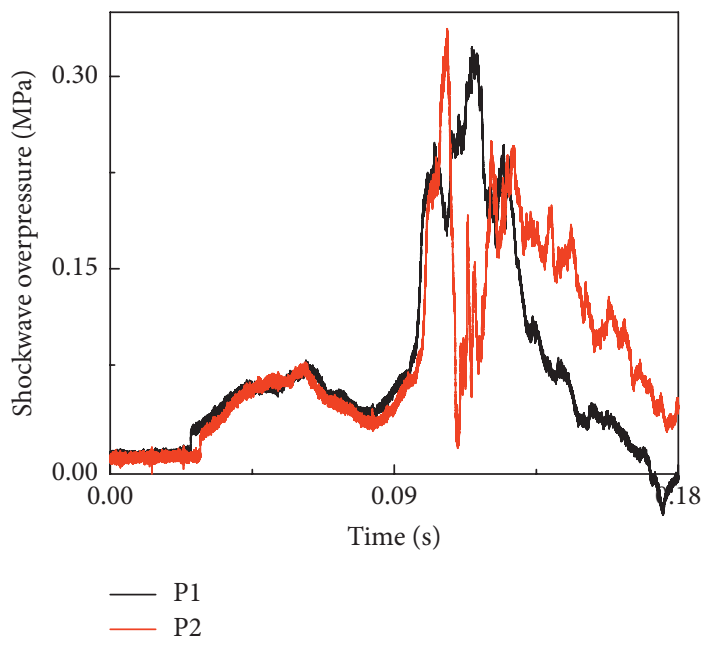

(a)

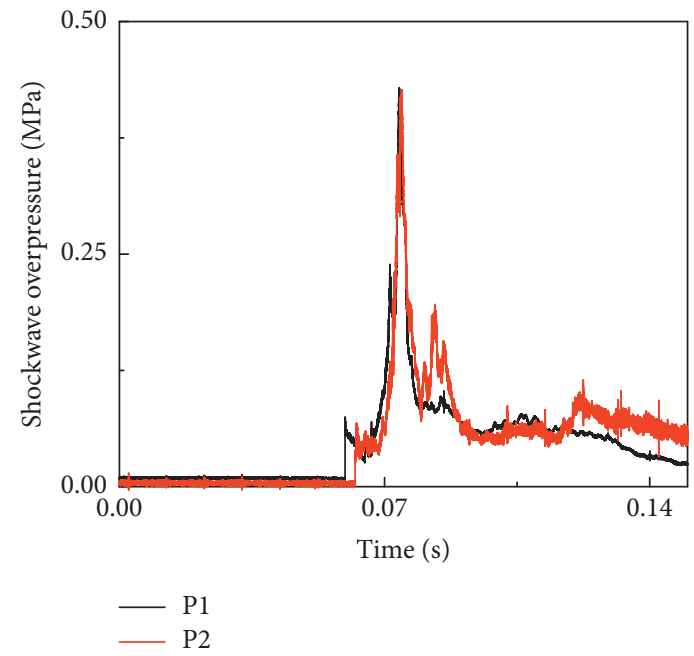

(c)

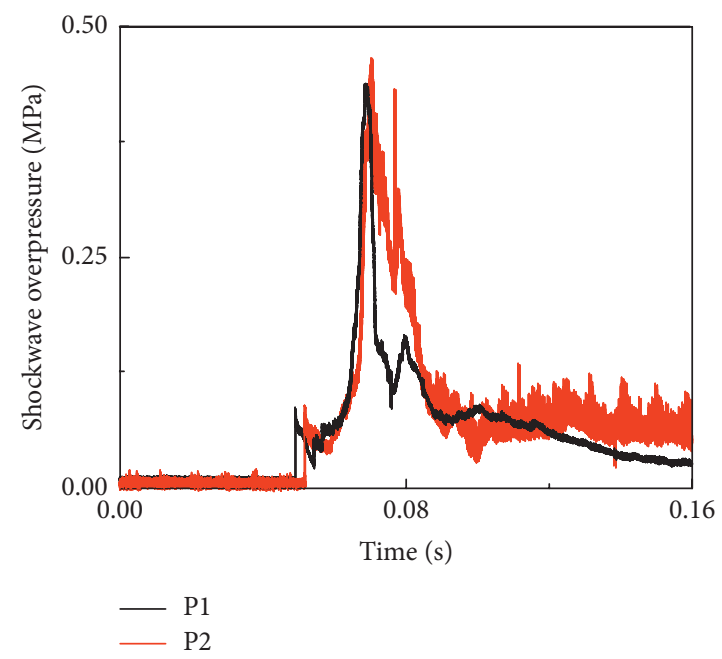

(b)

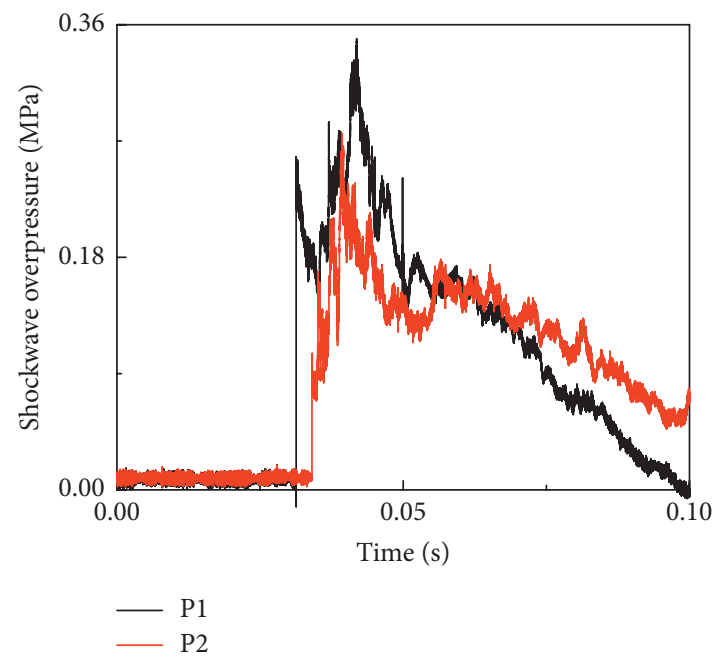

(d)

Figure 3: Explosion overpressure-time curve at the chamber inlet and outlet. (a) Pipeline section without a chamber; (b) chamber of L0.5 m $\times$ W0.3 m $\times$ H0.2 m; (c) chamber of L0.5 m $\times$ W0.5 m $\times$ H $0.2 \mathrm{~m}$; (d) chamber of L0.5 m $\times$ W0.8 m $\times$ H0.2 m.

respectively, the effect of the chamber on suppressing explosion propagation improves with the increase in the chamber width. When the chamber width is increased to $0.8 \mathrm{~m}$, the chamber has a suppressing effect on the explosion shockwave propagation.

2.3.2. Suppression of Explosion Flame Propagation by Chambers with Different Geometric Parameters. Figure 4 shows the evolution process of the explosion flame at each monitoring point in the experiment of gas explosion in a pipeline section without a chamber and the explosion suppression experiment using different chambers. The flame size is defined as the time integral of the optical signal collected by the flame sensor.

Figure 4(a) shows that, in the experiment of gas explosion in a pipeline section without a chamber, the flame size measured at the points F1 and F2 is 0.0613 and 0.0579 , respectively, which shows that a slight suppression of the flame occurred at F2, with an attenuation ratio of 5.54\%.

In Figure 4(b), in the explosion suppression experiment with the chamber of $\mathrm{L} 0.5 \mathrm{~m} \times \mathrm{W} 0.3 \mathrm{~m} \times \mathrm{H} 0.2 \mathrm{~m}$, the flame size measured at the points F1 and F2 is 0.0614 and 0.0594, respectively, which means that after passing through the chamber, the flame at F2 was slightly attenuated, with an attenuation ratio of $3.26 \%$. Compared with the pipeline section without a chamber, the explosion flame measured at points $\mathrm{F} 1$ and $\mathrm{F} 2$ in this experiment was attenuated by $-0.16 \%$ and $2.5 \%$, respectively, which shows that the flame size did not change significantly.

Figure 4(c) shows that, with the chamber of L0.5 $\mathrm{m} \times \mathrm{W} 0.5 \mathrm{~m} \times \mathrm{H} 0.2 \mathrm{~m}$, the flame size measured at the points F1 and F2 is 0.0409 and 0.0325 , respectively, which means that after passing through the chamber, the flame at F2 was significantly attenuated, by approximately $20.5 \%$. Compared with the pipeline section without a chamber, the 


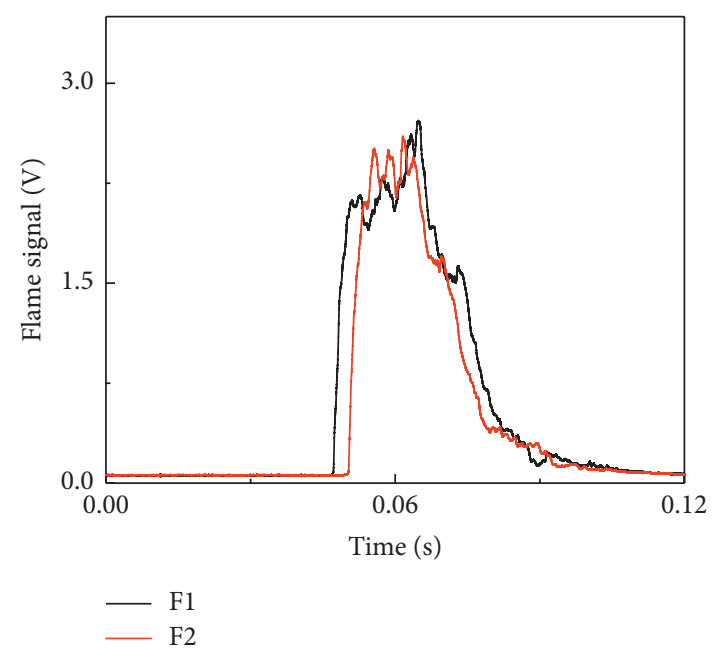

(a)

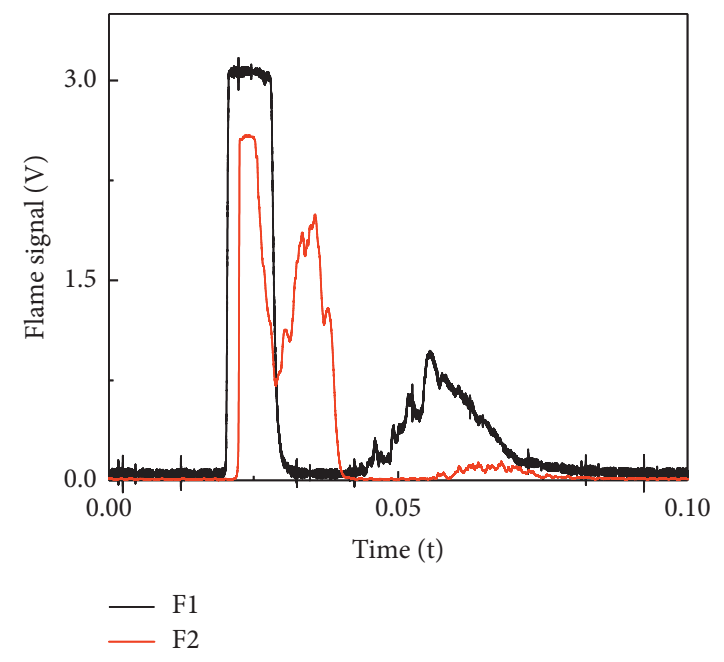

(c)

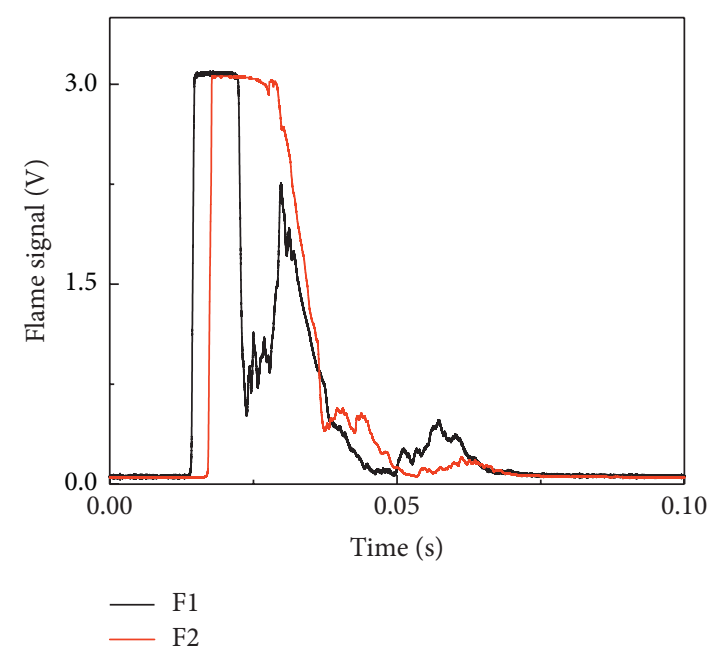

(b)

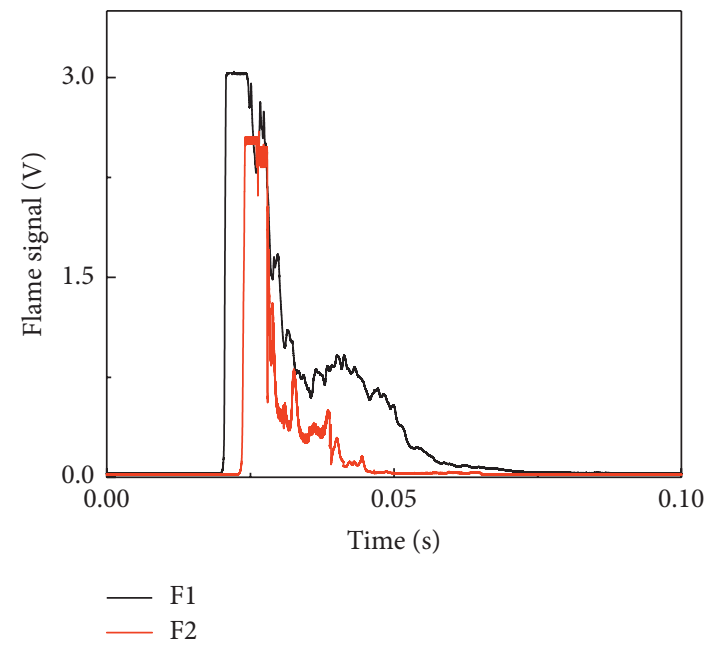

(d)

Figure 4: Explosion flame-time curve at the chamber inlet and outlet. (a) Pipeline section without a chamber; (b) chamber of $\mathrm{L} 0.5 \mathrm{~m} \times \mathrm{W} 0.3 \mathrm{~m} \times \mathrm{H} 0.2 \mathrm{~m}$; (c) chamber of L0.5 m $\times$ W0.5 m $\times \mathrm{H} 0.2 \mathrm{~m}$; (d) chamber of L0.5 $\mathrm{m} \times \mathrm{W} 0.8 \mathrm{~m} \times \mathrm{H} 0.2 \mathrm{~m}$.

explosion flame size at points F1 and F2 was attenuated by $33.27 \%$ and $43.8 \%$, respectively. This high attenuation ratio shows that the chamber used in this experiment had a strong suppressing effect on the propagation of the explosion flames.

Figure 4(d) shows that when the chamber of L0.5 $\mathrm{m} \times \mathrm{W} 0.8 \mathrm{~m} \times \mathrm{H} 0.2 \mathrm{~m}$ is used for flame suppression, the flame magnitude at the points F1 and F2 is 0.0402 and 0.0204, respectively, which means that the flame was significantly attenuated at $\mathrm{F} 2$, with an attenuation ratio of $49.2 \%$. Compared with the pipeline section without a chamber, the explosion flame size at points F1 and F2 was attenuated by $34.4 \%$ and $64.7 \%$, respectively. This high attenuation ratio shows that the chamber used in this experiment had a strong suppressing effect on the gas explosion flames propagation.

The above experimental results show that when the chamber length and height are constant at $0.5 \mathrm{~m}$ and $0.2 \mathrm{~m}$, respectively, the suppressing effect of the chamber on the propagation of the explosion flames improves as the chamber width increases. When the chamber width is $0.3 \mathrm{~m}$, the chamber has no suppressing effect on flame propagation; when the chamber width is increased to $0.5 \mathrm{~m}$, the chamber has a suppressing effect on flame propagation, and as the chamber width is increased further, its suppression effect is enhanced.

\section{Numerical Simulation of the Explosion Suppression Effect of Chambers with Different Geometric Parameters}

To further explore the influence rule of chamber geometry on its explosion suppression effect, a numerical model based on the experimental results described in the preceding section was established, and a numerical simulation of the gas explosion propagation process was carried out using five types of chambers with a length, width, and 
height of $0.5 \mathrm{~m} \times 0.3 \mathrm{~m} \times 0.2 \mathrm{~m}, \quad 0.5 \mathrm{~m} \times 0.5 \mathrm{~m} \times 0.2 \mathrm{~m}$, $0.5 \mathrm{~m} \times 0.8 \mathrm{~m} \times 0.2 \mathrm{~m}, \quad 0.3 \mathrm{~m} \times 0.5 \mathrm{~m} \times 0.2 \mathrm{~m}$, and $0.8 \mathrm{~m} \times$ $0.5 \mathrm{~m} \times 0.2 \mathrm{~m}$, respectively.

3.1. Geometric Model and Boundary Conditions. The geometric model and meshing are shown in Figure 5. The $X, Y$, and $Z$ dimensions of the simulated area are $36 \mathrm{~m}, 0.8 \mathrm{~m}$ (or $0.3 \mathrm{~m}$ or $0.5 \mathrm{~m}$ ), and $0.2 \mathrm{~m}$, respectively, and the number of mesh cells in the corresponding directions is 1800,40 (or 15 or 25), and 10 . In this model, the $11 \mathrm{~m}$-long detonation segment is on the left side of the model; the detonation segment is a pipe filled with a premixed $10 \%$ methane-air gas mixture. The propagation segment is on the right side of the model. The propagation segment is $22.5 \mathrm{~m}$ long and consists of a pipe with an outer diameter of $0.2 \mathrm{~m}$ and a rectangular chamber. The two pressure monitoring points $\mathrm{P} 1$ and $\mathrm{P} 2$ are located at a distance of $13.25 \mathrm{~m}(0.25 \mathrm{~m}$ from the chamber's inlet $)$ and $13.75+x \mathrm{~m}(0.25 \mathrm{~m}$ from the chamber's outlet, $x$ is the chamber's length along the $X$-axis), respectively, from the ignition electrode.

The initial conditions of the model are as follows: The initial pressure, initial density gradient, and initial temperature in the pipeline are $0.1 \mathrm{MPa}, 0$, and $293 \mathrm{~K}$, respectively. The boundary conditions of the model are as follows: The inner walls of the pipeline and chamber allow for adiabatic flow with no slip.

3.2. Mathematical Model and Numerical Method. The model is based on the following assumptions: The gas explosion is an adiabatic expansion process of an ideal gas; the gas explosion reaction is assumed to be a single-step reversible process; the thermal radiation is ignored; and the fluid-solid coupling effect between the impact flow and the solid inner wall is ignored.

The gas explosion process satisfies the conditions of the conservation of energy, mass, and momentum equations, as well as of the turbulent kinetic energy, turbulent energy dissipation rate, fuel component, and mixture component equations, which can all be expressed in a unified form as [21]

$$
\begin{aligned}
\frac{\partial}{\partial t}(\rho \phi)+\frac{\partial}{\partial x_{j}}\left(\rho u_{j} \phi\right) & =\frac{\partial}{\partial x_{j}}\left(\Gamma \phi \frac{\partial \phi}{\partial x_{j}}\right)+S \phi, \\
\Gamma \phi & =\frac{\mu_{e f f}}{\sigma \phi},
\end{aligned}
$$

where $t$ is time, $\rho$ is the density, $\phi$ is a general variable, $\partial / \partial t(\rho \phi)$ is an unsteady term, $u_{j}$ is the velocity component in the $x$-direction, $x_{j}$ represents the spatial coordinates $(j=1,2,3, \ldots), \partial / \partial x_{j}\left(\rho u_{j} \phi\right)$ is a convection term, $\Gamma \phi$ is the exchange coefficient of the flux $\phi, \mu_{e f f}$ is the effective viscosity, $\sigma \phi$ is the Prandtl number, $\partial / \partial x_{j}\left(\Gamma \phi\left(\partial \phi / \partial x_{j}\right)\right)$ is a diffusion term, and $S \phi$ is the energy source term.

In the numerical simulation, the $\mathrm{k}-\varepsilon$ turbulence model is used to deal with turbulence in the combustion process; the wall surface function is adopted to treat the variations in the flow field close to the wall area. The control volume integration method, the staggered grid method, and the semi-implicit method for pressure linked equations (SIMPLE) algorithm were used to solve the pressure-velocity coupling based on the segregated approach; the incremental method and the backward difference method were used to discretize the control equations of the chemical reaction field, the material structure field, and the chemical flow field [22].

3.3. Numerical Simulation Results. Figure 6 shows the explosion overpressure-time curve measured at each monitoring point of the pipeline section without a chamber and with different-size chambers; the maximum value of shockwave overpressure and the attenuation ratio at each monitoring point are listed in Table 1.

Comparing the experimental results with the numerical simulation results, the experimental overpressure measured at each monitoring point is slightly greater than its simulated counterparts. This is because of the polyethylene film installed between the propagation segment and the detonation segment in the experiment; the turbulence generated when the membrane is broken accelerates the reaction. At the same time, owing to the limitations of the processing technology, the inner wall of the pipeline and chambers as well as the connecting joints are not perfectly smooth and flat. For these reasons, the experimental values of the overpressure are greater than the simulated values. Nevertheless, the experimental results and simulation results show consistent trends of explosion overpressure propagation.

\subsubsection{Suppression of Shockwave Propagation by Variable-} Width Chambers with Constant Length of $0.5 \mathrm{~m}$ and Height of $0.2 \mathrm{~m}$. From Table 1 and Figures 6(a), 6(c)-6(e), it can be observed that when the chamber of L0.5 $\mathrm{m} \times \mathrm{W} 0.3$ $\mathrm{m} \times \mathrm{H} 0.2 \mathrm{~m}$ is used, the attenuation ratio of the overpressure after passing through the chamber is $-3.85 \%$. In addition, compared with the corresponding locations on the pipeline section without a chamber, the gas explosion overpressure attenuation ratio at the chamber inlet P1 and outlet P2 is $-36.19 \%$ and $-38.04 \%$, respectively, which shows that this chamber enhances the propagation of explosion shockwave. When the chamber of L $0.5 \mathrm{~m} \times \mathrm{W} 0.5 \mathrm{~m} \times \mathrm{H} 0.2 \mathrm{~m}$ is used, the overpressure attenuation ratio after passing through the chamber is $0.88 \%$, and compared with the pipeline section without a chamber, the attenuation ratio at the inlet $\mathrm{P} 1$ and outlet $\mathrm{P} 2$ is $-30.40 \%$ and $-26.15 \%$, respectively, which shows that this chamber enhances the propagation of the shockwave. When the chamber of L0.5 $\mathrm{m} \times \mathrm{W} 0.8 \mathrm{~m} \times \mathrm{H} 0.2 \mathrm{~m}$ is used, the overpressure attenuation ratio after passing the chamber is $13.73 \%$, and compared with the pipeline section without a chamber, the attenuation ratio at P1 and P2 is $-6.16 \%$ and $10.61 \%$, respectively. Although the shockwave overpressure at the chamber inlet was increased slightly, it was significantly weaker at the chamber outlet, which shows that this chamber had a suppression effect on the explosion overpressure. 


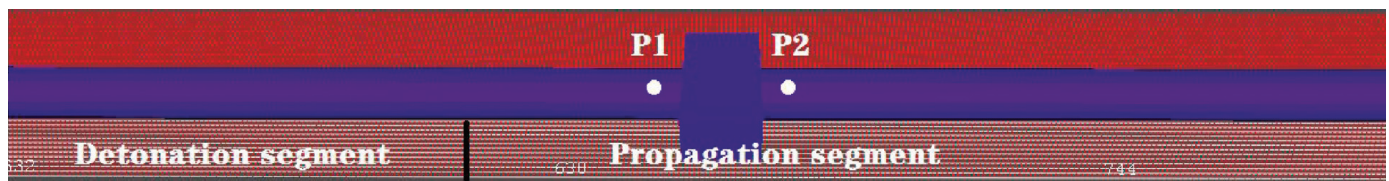

Figure 5: Geometric model and meshing.

The above results show that when the chamber length and height are constant at $0.5 \mathrm{~m}$ and $0.2 \mathrm{~m}$, respectively, its explosion suppression effect improves with an increase in the chamber width; when the chamber width increases to $0.8 \mathrm{~m}$, the chamber can effectively suppress the propagation of explosion shockwave. The numerical simulation results and the experimental results are consistent, which means that the numerical model is reliable.

\subsubsection{Suppression of Shockwave Propagation by Variable-} Length Chambers with Constant Width of $0.5 \mathrm{~m}$ and Height of $0.2 \mathrm{~m}$. From Table 1 and Figures 6(a), 6(b), 6(d), and 6(f), it can be observed that for the chamber of $\mathrm{L} 0.3 \mathrm{~m} \times \mathrm{W} 0.5 \mathrm{~m} \times \mathrm{H} 0.2 \mathrm{~m}$, the overpressure is attenuated by $-0.64 \%$ after passing through the chamber, and compared with the pipeline section without a chamber, the shockwave overpressure at the inlet P1 is attenuated by $-17.46 \%$ and at the outlet $\mathrm{P} 2$ is attenuated by $-16.01 \%$, which shows that this chamber enhanced the propagation of the shockwave. For the chamber of $\mathrm{L} 0.5 \mathrm{~m} \times \mathrm{W} 0.5 \mathrm{~m} \times \mathrm{H} 0.2 \mathrm{~m}$, the overpressure is attenuated by $0.88 \%$ after passing through the chamber, and compared with the pipeline section without a chamber, the overpressure at $P 1$ is attenuated by $-30.40 \%$, and at $\mathrm{P} 2$, overpressure is attenuated by $-26.15 \%$, which indicates that this chamber also enhanced the propagation of the explosion shockwave. For the chamber of $\mathrm{L} 0.8 \mathrm{~m} \times \mathrm{W} 0.5 \mathrm{~m} \times \mathrm{H} 0.2 \mathrm{~m}$, the overpressure attenuation ratio after passing through the chamber is $8.77 \%$, and compared with the pipeline section without a chamber, the overpressure is attenuated by $-33.74 \%$ at $\mathrm{P} 1$ and by $-14.16 \%$ at $\mathrm{P} 2$, which shows that this chamber also enhanced the propagation of shockwave.

These results show that when the chamber height and width are constant at $0.2 \mathrm{~m}$ and $0.5 \mathrm{~m}$, respectively, the chamber has an enhancing effect on shockwave at the inlet, and the shockwave overpressure increases as the chamber length increases. The enhancement effect on the overpressure is stronger at the chamber outlet and weaker at its inlet, and as the chamber length increases, the shockwave overpressure first increases and then decreases. Therefore, the three types of chambers with a constant height of $0.2 \mathrm{~m}$ and width of $0.5 \mathrm{~m}$ are not effective in suppressing the propagation of explosion shockwave.

\section{Influence of Chamber Geometrical Parameters on Effect of Explosion Propagation Suppression and Its Mechanism Analysis}

The propagation of the explosion flame and the premixed gas in the chamber can be obtained from the numerical simulation. Figure 7 shows the propagation process of the explosion flame in different chambers at certain times; the colour legend on the far right shows the flame temperature. Figure 8 shows the propagation of the premixed gas in the chamber at the times corresponding to those in Figure 7; the colour bar on the far right shows the mass fraction of methane. It is evident from Figures 7 and 8 that the premixed gas enters the chamber under the impulse of the flame precursor shockwave. Owing to the sudden expansion of the propagation space, the premixed gas is dissipated in the chamber under the action of the shockwave and advances rapidly in the same direction as the propagation segment. Some of the dissipated gas develops turbulent flow under the action of the shockwave, and some of it is diluted by the air in the chamber and ignited by the flame immediately afterwards. This causes an explosion inside the chamber, in which the secondary shockwave generated by the explosion collides with the initial shockwave and then propagates out of the chamber [23]. Therefore, the strength of the secondary shockwave directly affects the explosion suppression effect of the chamber, and the strength of the secondary shockwave is determined by the amount of methane consumed in the chamber.

Figure 9 shows the change over time in the methane mass concentration measured at the outlets of different chambers. The time integral values can be used to characterise the remaining amount of methane after the premixed gas passes through the chamber. Accordingly, the residual amount of methane for the chambers of L0.3 $\mathrm{m} \times \mathrm{W} 0.5 \mathrm{~m} \times \mathrm{H} \quad 0.2 \mathrm{~m}, \quad \mathrm{~L} 0.5 \mathrm{~m} \times \mathrm{W} 0.3 \mathrm{~m} \times \mathrm{H} 0.2 \mathrm{~m}$, L0.5 m $\times$ W0.5 m $\times$ H $0.2 \mathrm{~m}, \mathrm{~L} 0.5 \mathrm{~m} \times \mathrm{W} 0.8 \mathrm{~m} \times \mathrm{H} 0.2 \mathrm{~m}$, and $\mathrm{L} 0.8 \mathrm{~m} \times \mathrm{W} 0.5 \mathrm{~m} \times \mathrm{H} 0.2 \mathrm{~m}$ is $0.09337,0.07571,0.07615$, 0.11193 , and 0.04318 , respectively. Because the same amount of methane enters each chamber, if there is a reduction in the residual amount of methane after the gas mixture passes through the chamber, then it follows that the more methane reacts in the chamber, the greater will be the explosion energy that is released, and a stronger explosion shockwave will be produced. Figure 9(a) shows that when the chamber length is constant at $0.5 \mathrm{~m}$, as the chamber width increases, the residual amount of methane at the chamber outlet gradually increases; for example, after passing through the chambers of $\mathrm{L} 0.5 \mathrm{~m} \times \mathrm{W} 0.5 \mathrm{~m} \times \mathrm{H} 0.2 \mathrm{~m}$ and L0.5 m $\times$ W0.8 m $\times$ H0.2 m, a secondary methane-air mixture appears, but its mass fraction is below the lower explosive limit. The reason for this is that after the premixed methane-air gas enters the chamber, part of the premixed gas is diluted by the air present in the chamber, causing it to lose its explosive characteristics. As the chamber width increases, the amount of methane that reacts in the chamber decreases; hence, the secondary shockwave generated in the reaction weakens. In addition, the explosion relief capacity 

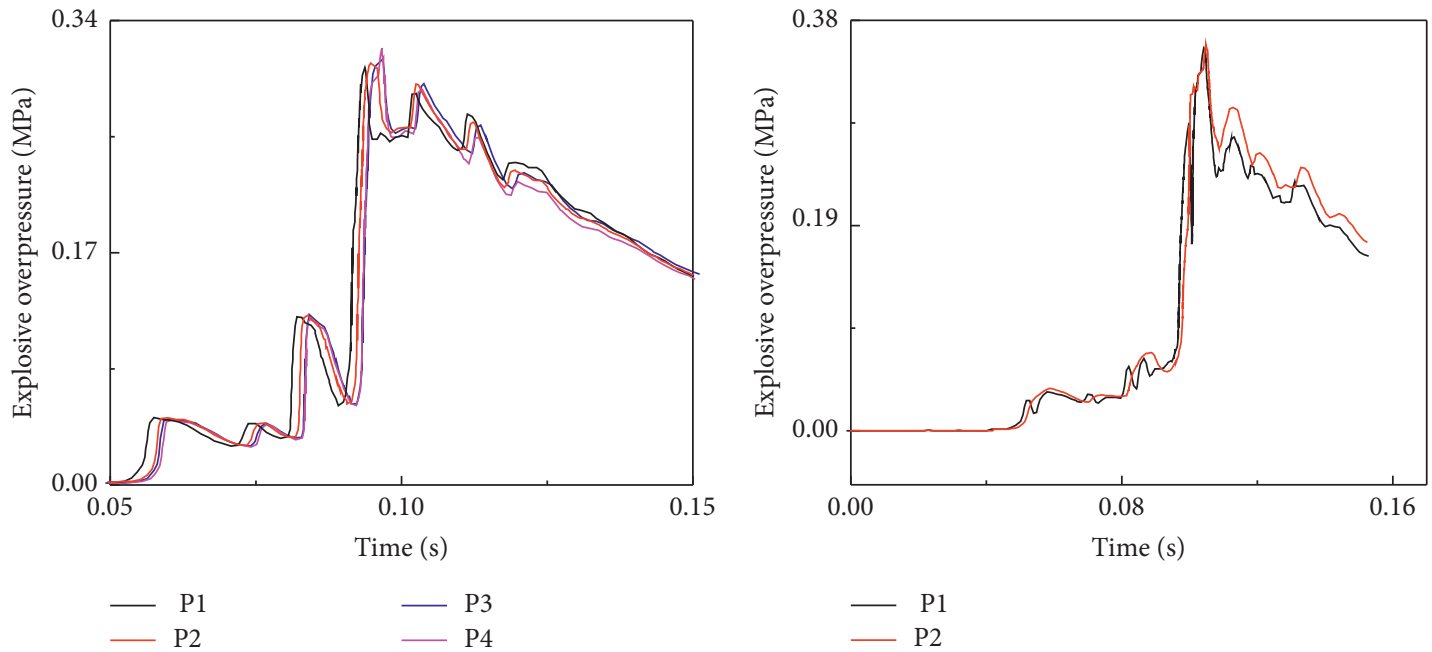

(a)
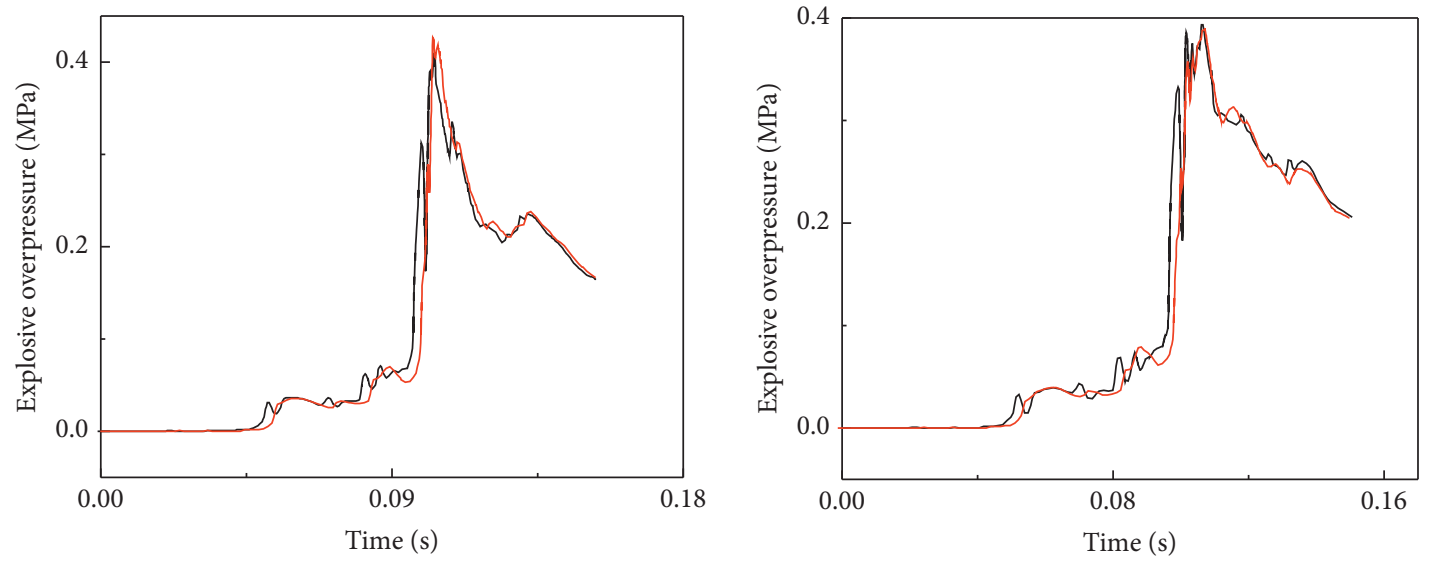

- P1

- P1

- P2

(c)

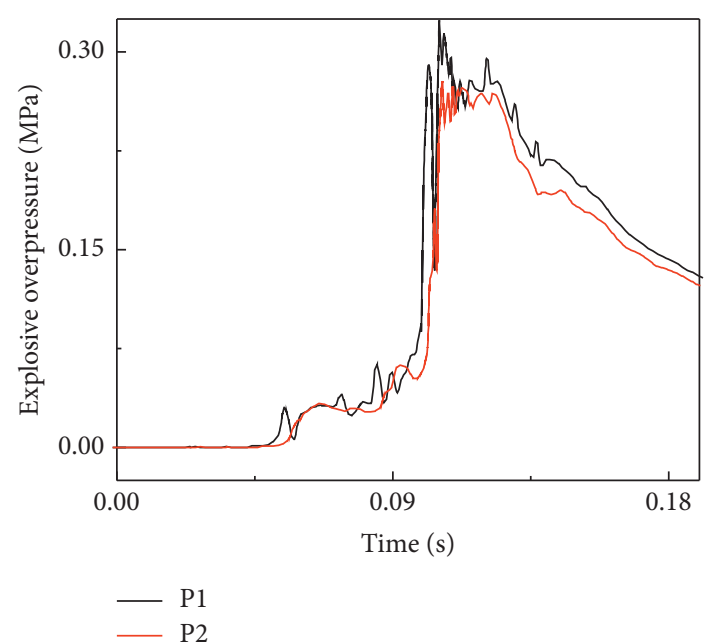

(d)

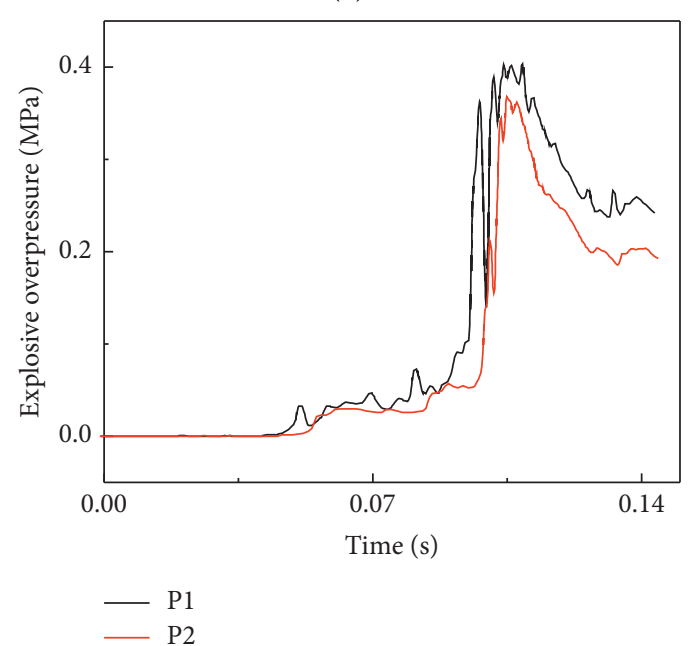

(e)

(f)

Figure 6: Explosion overpressure-time curve at the chamber inlet and outlet. (a) Pipeline section without a chamber; (b) chamber of $\mathrm{L} 0.3 \mathrm{~m} \times \mathrm{W} 0.5 \mathrm{~m} \times \mathrm{H} 0.2 \mathrm{~m}$; (c) chamber of $\mathrm{L} 0.5 \mathrm{~m} \times \mathrm{W} 0.3 \mathrm{~m} \times \mathrm{H} 0.2 \mathrm{~m}$; (d) chamber of $\mathrm{L} 0.5 \mathrm{~m} \times \mathrm{W} 0.5 \mathrm{~m} \times \mathrm{H} 0.2 \mathrm{~m}$; (e) chamber of L0.5 m $\times$ W0.8 m $\times$ H0.2 m; (f) chamber of L0.8 m $\times$ W0.5 m $\times$ H0.2 m. 
TABLE 1: Maximum overpressure and overpressure attenuation ratio at each monitoring point of the pipeline section without a chamber and with different chambers.

\begin{tabular}{|c|c|c|c|c|c|c|c|}
\hline \multirow[b]{2}{*}{$\begin{array}{l}\text { Chamber dimensions } \\
\text { (length } \times \text { width } \times \text { height })\end{array}$} & \multicolumn{4}{|c|}{$\begin{array}{l}\text { Maximum overpressure at each monitoring } \\
\text { point }(\mathrm{MPa})\end{array}$} & \multirow{2}{*}{$\begin{array}{c}\text { Overpressure } \\
\text { attenuation ratio } \\
\text { after passing the } \\
\text { chamber }(\%)\end{array}$} & \multirow{2}{*}{$\begin{array}{c}\text { Overpressure } \\
\text { attenuation ratio at } \\
\text { chamber inlet } \\
\text { relative to no- } \\
\text { chamber pipeline } \\
(\%)\end{array}$} & \multirow{2}{*}{$\begin{array}{c}\text { Overpressure } \\
\text { attenuation ratio at } \\
\text { chamber outlet } \\
\text { relative to no- } \\
\text { chamber pipeline } \\
(\%)\end{array}$} \\
\hline & $\begin{array}{l}13.25 \mathrm{~m} \\
\text { from the } \\
\text { ignition } \\
\text { electrode }\end{array}$ & $\begin{array}{l}14.05 \mathrm{~m} \\
\text { from the } \\
\text { ignition } \\
\text { electrode }\end{array}$ & $\begin{array}{l}14.25 \mathrm{~m} \\
\text { from the } \\
\text { ignition } \\
\text { electrode }\end{array}$ & $\begin{array}{l}14.55 \mathrm{~m} \\
\text { from the } \\
\text { ignition } \\
\text { electrode }\end{array}$ & & & \\
\hline $\begin{array}{l}\text { Pipeline section only (no } \\
\text { chamber) }\end{array}$ & 0.3053 & 0.3111 & 0.3128 & 0.3263 & - & - & - \\
\hline $0.3 \mathrm{~m} \times 0.5 \mathrm{~m} \times 0.2 \mathrm{~m}$ & 0.3586 & 0.3609 & - & - & -0.64 & -17.46 & -16.01 \\
\hline $0.5 \mathrm{~m} \times 0.3 \mathrm{~m} \times 0.2 \mathrm{~m}$ & 0.4158 & - & 0.4318 & - & -3.85 & -36.19 & -38.04 \\
\hline $0.5 \mathrm{~m} \times 0.5 \mathrm{~m} \times 0.2 \mathrm{~m}$ & 0.3981 & - & 0.3946 & - & 0.88 & -30.40 & -26.15 \\
\hline $0.5 \mathrm{~m} \times 0.8 \mathrm{~m} \times 0.2 \mathrm{~m}$ & 0.3241 & - & 0.2796 & - & 13.73 & -6.16 & 10.61 \\
\hline $0.8 \mathrm{~m} \times 0.5 \mathrm{~m} \times 0.2 \mathrm{~m}$ & 0.4083 & - & - & 0.3725 & 8.77 & -33.74 & -14.16 \\
\hline
\end{tabular}

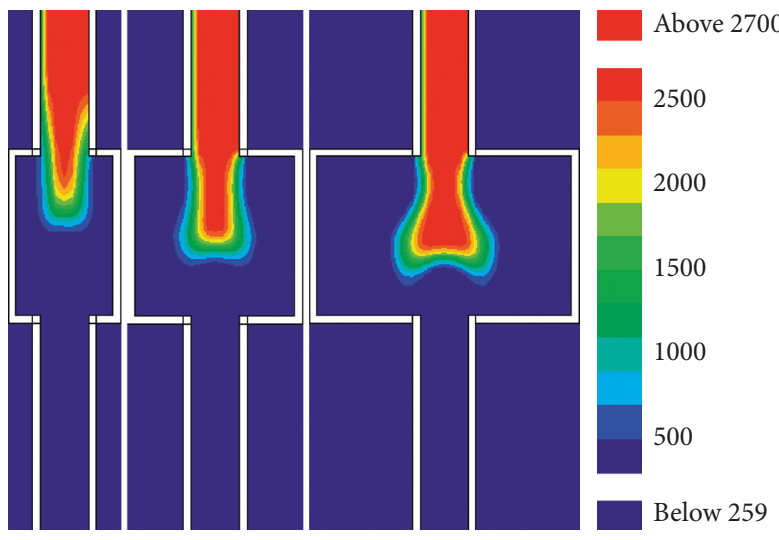

(a)

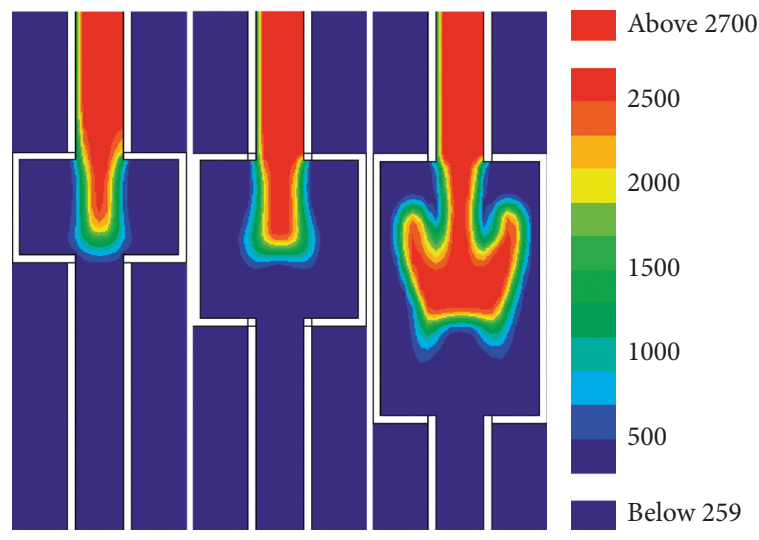

(b)

Figure 7: Propagation of explosion flame in chambers with different geometric parameters. (a) Variable-width chambers (0.2 $\mathrm{m}$ high and $0.5 \mathrm{~m}$ long); (b) variable-length chambers $(0.2 \mathrm{~m}$ high and $0.5 \mathrm{~m}$ wide).

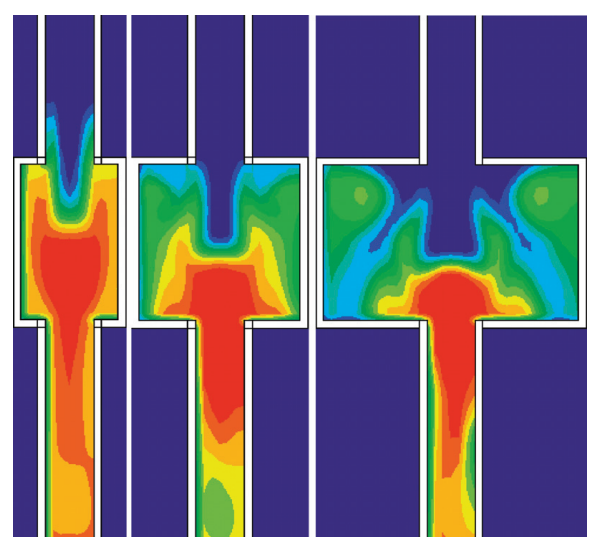

(a)

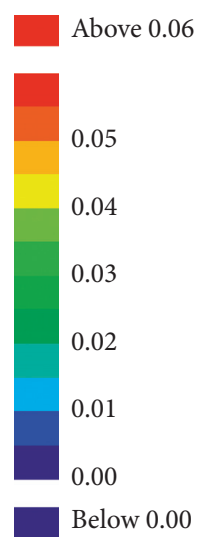

Below 0.00
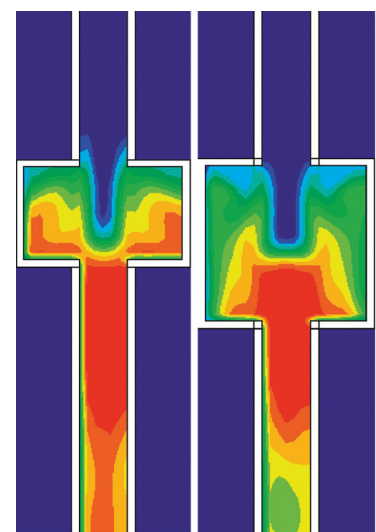

(b)

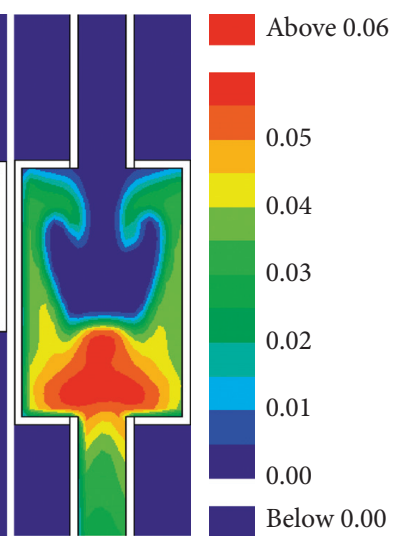

)

FIGURE 8: Propagation of premixed methane in chambers with different geometric parameters. (a) Variable-width chambers $(0.2 \mathrm{~m}$ high and $0.5 \mathrm{~m}$ long); (b) variable-length chambers $(0.2 \mathrm{~m}$ high and $0.5 \mathrm{~m}$ wide).

of the chamber increases rapidly with the increase in the chamber width, so when the chamber's relief capacity is sufficient to accommodate the secondary shockwave, the chamber has an explosion suppression effect. Accordingly, when the chamber width increases to $0.8 \mathrm{~m}$, the chamber can effectively suppress the propagation of explosion shockwave. It is evident from Figure 9(b) that when the chamber width is fixed at $0.5 \mathrm{~m}$, as the chamber length increases, the amount of premixed gas participating in the chemical reaction inside the chamber gradually increases, and the secondary 


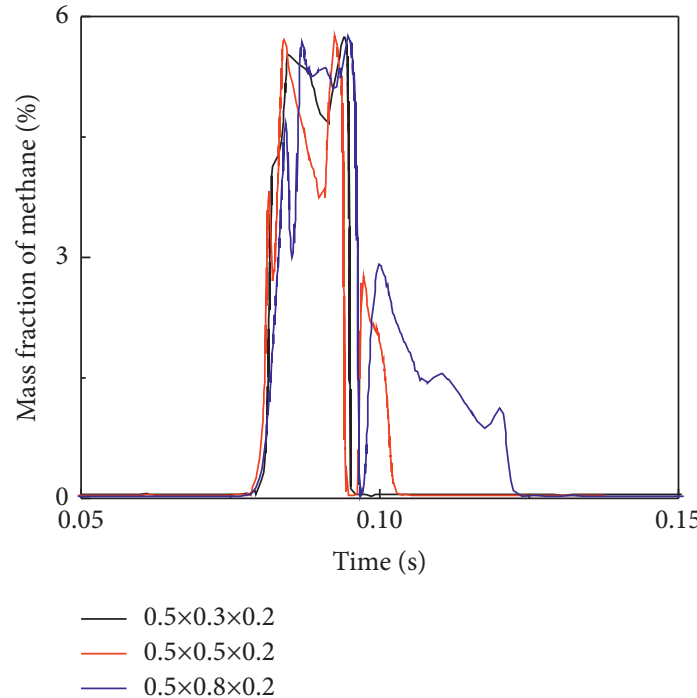

(a)

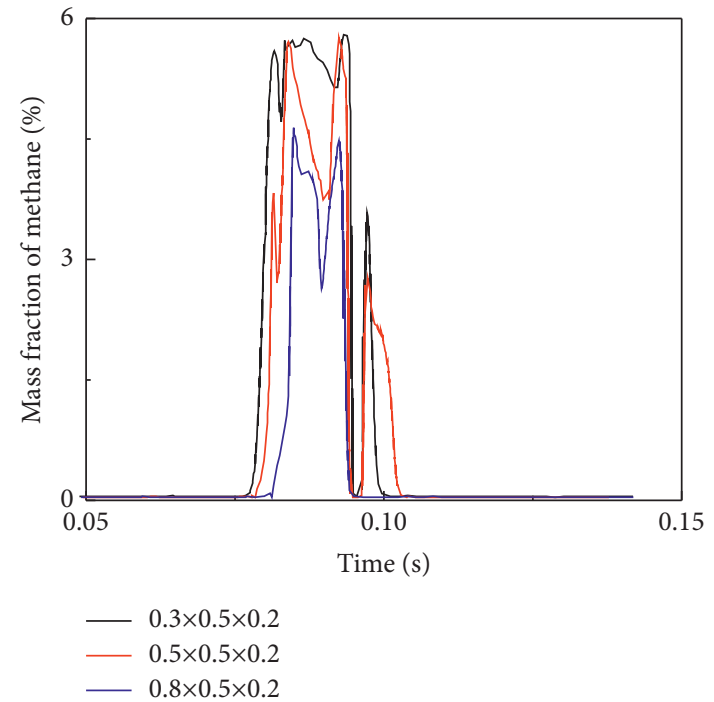

(b)

Figure 9: Methane mass concentration at the outlet of chambers with different geometric parameters. (a) Variable-width chambers (0.2 $\mathrm{m}$ high and $0.5 \mathrm{~m}$ long); (b) variable-length chambers ( $0.2 \mathrm{~m}$ high and $0.5 \mathrm{~m}$ wide).

shockwave inside the chamber expands. At the same time, even though the explosion relief capacity of the chamber increases rapidly with the increase in its length, its relief capacity is still insufficient to suppress the secondary shockwave generated by the chemical reaction inside the chamber. Therefore, none of the three chambers with different lengths and a constant width of $0.5 \mathrm{~m}$ are effective in suppressing the propagation of shockwave from gas explosions.

\section{Conclusions}

(1) In this study, an experiment involving three types of chambers with fixed heights and lengths and variable widths (with the length, width, and height of $0.5 \mathrm{~m} \times 0.3 \mathrm{~m} \times 0.2 \mathrm{~m}, \quad 0.5 \mathrm{~m} \times 0.5 \mathrm{~m} \times 0.2 \mathrm{~m}, \quad$ and $0.5 \mathrm{~m} \times 0.8 \mathrm{~m} \times 0.2 \mathrm{~m}$, respectively) was carried out with the following results. The suppression effect of chambers on the explosion shockwave improves with the increase in the chamber width; when the chamber width increases to $0.8 \mathrm{~m}$, the chamber inhibits the propagation of explosion shockwave. In addition, the flame suppression effect of the chamber also improves with the increase in the chamber width; when the chamber width increases to $0.5 \mathrm{~m}$, the chamber has a suppressing effect on the propagation of flames.

(2) The numerical simulation results obtained in this study are as follows: when the chamber height and length are constant at $0.2 \mathrm{~m}$ and $0.5 \mathrm{~m}$, respectively, the explosion suppression effect of the chamber improves with the increase in the chamber width; when the chamber width increases to $0.8 \mathrm{~m}$, the overpressure at the chamber outlet is attenuated by $10.61 \%$, indicating that the chamber has the effect on suppressing the propagation of explosion shockwave, which is consistent with the experimental results in this study. When the chamber height and width are constant at $0.2 \mathrm{~m}$ and $0.5 \mathrm{~m}$, respectively, as the chamber width increases, the overpressure suppression effect at the chamber outlet first increases and then weakens. When the chamber width increases to $0.8 \mathrm{~m}$, the overpressure at the outlet is attenuated by $-14.16 \%$, which shows that the chamber does not suppress the propagation of shockwave.

(3) Using a numerical simulation of the propagation process of the explosion flames and premixed methane-air gas in different chambers, the effect of the chamber geometry on the explosion suppression mechanism is analysed. It is found that when the chamber height and length are fixed at $0.2 \mathrm{~m}$ and $0.5 \mathrm{~m}$, respectively, as the chamber width increases, the amount of the methane mixture participating in the chemical reaction inside the chamber gradually decreases, and hence, the secondary shockwave in the chamber weakens. At the same time, as the chamber width increases, the explosion relief capacity of the chamber increases rapidly. When the explosion relief capacity is sufficient to accommodate the secondary shockwave, the chamber has a suppressing effect on explosion shockwave. When the chamber height and width are fixed at $0.2 \mathrm{~m}$ and $0.5 \mathrm{~m}$, respectively, as the chamber length increases, the amount of premixed gas participating in the chemical reaction inside the chamber gradually increases, and the secondary explosion shockwave in the chamber also increases. Although the explosion relief capacity of the chamber increases rapidly with the increase in the chamber length, it is not sufficient 
to suppress the secondary shockwave generated in the chemical reaction inside the chamber; therefore, the chamber has no explosion suppression effect.

\section{Data Availability}

The data can be obtained by contacting Shujie Yuan and Chaomin Mu (yuansj@aust.edu.cn).

\section{Conflicts of Interest}

The authors declare that there are no conflicts of interest regarding the publication of this study.

\section{Acknowledgments}

This work was supported by the Natural Science Foundation of China (nos. 52074012 and 51874009), Education Department of Anhui Province (no. KJ2020A0323), and the Institute of Energy, Hefei Comprehensive National Science Center (no. 19KZS203).

\section{References}

[1] Y. J. Liu, L. Yuan, and J. H. Xue, "Analysis on the occurrence law of gas disaster accidents in coal mine from 2007 to 2016," Mining Safety and Environmental Protection, vol. 45, no. 3, pp. 124-128, 2018.

[2] G. O. Thomas, A. Jones, and M. J. Edwards, "Influence of water sprays on explosion development in fuel-air mixtures," Combustion Science and Technology, vol. 80, no. 1-3, pp. 47-61, 1991.

[3] M. J. Xu and S. X. Lu, "Sprinkler fire suppression experiments in large space," Ship \& Ocean Engineering, vol. 46, no. 3, pp. 94-97, 2017.

[4] X. S. Wang, X. D. Zhao, and B. H. Cong, "Experimental study on gaseous flame suppression with water mist," Journal of University of Science and Technology of China, vol. 1, pp. 26-28, 2006.

[5] H. L. Xu, Experimental Study on Mitigation of Menthane-Coal Dust Hybird Explosion with Ultra-fine Water Mist, University of Science and Technology of China, Hefei, China, 2013.

[6] M. S. Bi, Z. Li, and P. P. Zhang, "Experimental investigation on suppression of gas explosion with water mist," Journal of Mining and Safety Engineering, vol. 29, no. 3, pp. 440-443, 2012.

[7] M. G. Yu, X. N. Zhu, and B. Pei, "Experimental study on methane explosion suppression using carbon dioxide and ultra-fine water mist," Journal of China Coal Society, vol. 40, no. 12, pp. 2843-2848, 2015.

[8] P. Kosinski, "Explosion suppression by a cloud of particles: numerical analysis of the initial processes," Applied Mathematics and Computation, vol. 217, no. 11, pp. 5087-5094, 2011.

[9] M. Krasnyansky, "Prevention and suppression of explosions in gas-air and dust-air mixtures using powder aerosol-inhibitor," Journal of Loss Prevention in the Process Industries, vol. 19, no. 6, pp. 729-735, 2006.

[10] H. Wen, W. Cao, and K. K. Wang, "Experimental study on ABC dry powder to repress gas explosion," Journal of Safety Science and Technology, vol. 7, no. 6, pp. 9-12, 2011.

[11] R. T. E. Hermanns, A. A. Konnov, R. J. M. Bastiaans, and L. P. H. De Goey, "Laminar burning velocities of diluted
Hydrogen-Oxygen-Nitrogen mixtures," Energy \& Fuels, vol. 21, no. 4, pp. 1977-1981, 2007.

[12] H. Wang, L. M. Ge, and J. Deng, "Experimental study of using inert gas to suppress mine gas explosion," Mining Safety \& Environmental Protection, vol. 35, no. 1, pp. 4-7+91, 2008.

[13] J. W. Shao, C. J. Zhuang, and Z. R. Wang, "Explosion suppression effect of $\mathrm{CH} 4 /$ air by combined porous materials in a container piping system," Explosion and Shock Waves, vol. 38, no. 4, pp. 905-912, 2018.

[14] K. Zhao, G. F. Gao, and X. J. Wang, "Dimensional analysis and numerical simulation for impact-resistance performance of cylindrical shell structures," Journal of Vibration and Shock, vol. 33, no. 11, pp. 12-16, 2014.

[15] Z. Y. Wu and S. G. Jiang, Study on Suppression Effect of Gas Explosion under Vacuum Cavity, pp. 56-112, China University of Mining and Technology Press, Xuzhou, China, 2009.

[16] H. Shao, S. Jiang, X. Zhang, Z. Wu, K. Wang, and W. Zhang, "Influence of vacuum degree on the effect of gas explosion suppression by vacuum chamber," Journal of Loss Prevention in the Process Industries, vol. 38, pp. 214-223, 2015.

[17] H. Shao, S. G. Jiang, and Q. H. Li, "Influence of vacuum chamber volume on gas explosion suppression," Journal of Mining and Safety Engineering, vol. 31, no. 3, pp. 489-493, 2014.

[18] H. Shao, S. Jiang, X. He, Z. Wu, X. Zhang, and K. Wang, "Numerical analysis of factors influencing explosion suppression of a vacuum chamber," Journal of Loss Prevention in the Process Industries, vol. 45, pp. 255-263, 2017.

[19] Z. Q. Li, C. M. Mu, and D. K. Xu, "Influence of cavity length on shock wave propagation of gas explosion," Journal of Mining and Safety Engineering, vol. 35, no. 6, pp. 1293-1300, 2018.

[20] X. C. Li, B. S. Nie, and C. L. Yang, "Effect of gas concentration on kinetic characteristics of gas explosion in confined space," Chinese Journal of High Pressure Physics, vol. 31, no. 2, pp. 135-147, 2017.

[21] Z. M. Luo, Q. Zhang, and H. Wang, "Numerical simulation of gas explosion in confined space with FLACS," Journal of China Coal Society, vol. 38, no. 8, pp. 1381-1387, 2013.

[22] G. -F. Zhang, "Numerical simulation and optimization of reactive extrusion processes for free radical reaction," Shandong University, pp. 36-73, 2009.

[23] Z. Yan, S. Yuan, Z. Li, S. Gu, and C. Mu, "Study on inhibitory effect of cavity on gas explosion propagation," Geofluids, vol. 2021, no. 8, Article ID 6674425, 9 pages, 2021. 